\title{
Fragments with correction
}

final version; accepted for publication by Linguistic Inquiry

Anikó Lipták

LUCL, Leiden University

Run-of-the-mill fragments, like (1B), have propositional meaning, containing a predicate that is identical to the one in the fragment's antecedent. This correspondence is one of the crucial reasons why structural theories of ellipsis (like PF-deletion or LF copying accounts) assume that the fragment should be related to its fully pronounced version in (1B').

(1) A: Who are you shouting at?

B: My sister.

B': I am shouting at my sister.

This squib presents novel data where the same correspondence is not observed. In the novel data the original predicate cannot form part of the fragment in its ordinary meaning, posing a puzzle for the representation of the ellipsis site. After describing the relevant data in sections 1 and 2, section 3 shows that the puzzle cannot be solved with reference to a non-isomorphic underlier in the ellipsis site. Section 4 offers a solution in two steps. First, an account based on accommodation of the lexical content of the ellipsis site is sketched (section 4.1). This proposal is shown to be untenable in structural accounts to ellipsis due to violations of syntactic and lexical identity (section 4.2.), and the proposal is replaced by an account in terms of metalinguistic reference (mixed quotation) in the ellipsis site (section 4.3.). It is also pointed out that a quotation-based structural account is more parsimonious than a non-structural account of the data.

\section{The puzzle: Pom Pom dialogues}

In naturally occurring conversations, fragments answering a wh-question can be followed by an adversative continuation that negates the verb. The negated verb is usually pronounced with focal stress and supplies a correction with respect to the original predicate.
a. A: Where are you running to?
B: To school, but I am not running.
b. A: What are you devouring?
B: A pizza, but I am not devouring it.
c. A: Who are you shouting at?
B: My sister, but I am not shouting.

As the presumed non-elliptical versions of these fragments in (3) indicate, supplying the answers with the original predicate results in incongruence (indicated by \#): the first conjunct asserts a proposition and the second conjunct denies it. This leads to contradictory statements. 
(3) a. A: Where are you running to?

B: \# I am running to school, but I am not running.

b. A: What are you devouring?

B: \# I am devouring a pizza, but I am not devouring it.

c. A: Who are you shouting at?

B: \# I am shouting at my sister, but I am not shouting.

Importantly, while the answers in (3) contain incongruent responses to a question, the elliptical answers in (2) are not incongruent in the same way. They do not give the impression that the speaker is confused about the kind of event he was involved in or that he changes his mind halfway through his utterance.

Answers like (2) are natural responses to questions. As the Hungarian equivalent of (2a) is the recurring initial dialogue in the cartoon series Pom Pom meséi (Tales of Pom Pom, penned by István Csukás 1979/1980), this kind of question-answer pairs will be referred to as Pom Pom dialogues. While the rest of the paper will mostly use English examples for illustration, these dialogues are also natural in Dutch, Hungarian, Russian, Turkish and Japanese among possible other languages.

Pom Pom dialogues pose a puzzle for theories of ellipsis, as it is not evident what kind of predicate should be construed as part of the representation of the fragment. Assuming a structural approach according to which there is syntactic structure in the ellipsis site (reason for this choice will be provided in section 3), and a lexicalist stance according to which structure is built from lexical items, this work describes the puzzle and sketches a solution for it.

\section{Properties of Pom Pom dialogues}

Pom Pom dialogues contain a question about an event that in the view of the addressee is being wrongly characterized by the questioner. They require a specific context that allows the addressee to identify the event the questioner is referring to.

The matter of contention usually corresponds to the manner component of the predicate, which is indicated by the fact that speakers consulted consider Pom Pom answers natural with verbs that contain a manner component, such as manner of motion verbs (run, jog, rush, trot, stroll, march, hop), manner of speaking verbs (shout, cry, mumble, mutter, yell) or verbs of ingesting (devour, gobble, gulp, munch, nibble, gorge), such as the examples in (2). ${ }^{\mathrm{i}}$

Verbs without a manner component are perceived somewhat less natural, but perfectly acceptable given the right context and if the correct predicate is made explicit after the answer (such continuations are not needed in (2)). Virtually any kind of verb can be corrected this way.

a. context: Speaker A sees someone lying on the floor motionless
A: Who is sleeping there?
B: Frank, but he is not sleeping, he is dead.

b. context: Speaker A, who is blind, hears a hissing/creaking noise

A: What did you open?

B: The door, but I didn't open it, I closed it.

c. context: Speaker A hears speaker B talk negatively about some people 
A: Who do you hate most?

B: Sue. But I don't hate her, I find her irritating.

A further condition on felicious Pom Pom answers is that the antecedent verb needs to be backgrounded in the question, i.e. not form the focus of the utterance. Focused verbs cannot be given answers of this type (cf. 5).

(5) A: The kids have eaten lots of things in different ways. What have they DEVOURED?

B: A pizza. \# But they have not devoured it.

Note also that in addition to wh-questions, polar questions are suitable antecedents to contrastive Pom Pom fragments as long as they contain a contrastive element that is not the verb (cf. 6):
a. A: Are you running to SCHOOL?
B: No, to the PLAYGROUND. But I am not running.
b. A: Are you shouting at your SISTER?
B: No, at YOU! But I am not shouting.

Last, next to fragments, Pom Pom answers can also contain VP ellipsis (at least for the British English speakers consulted), provided the elliptical clause refers to a backgrounded verb:

(7) A: Who has rushed in just now?

B: John has, but he hasn't exactly rushed in.

\section{It-clefts do not come to our rescue}

Before providing a solution to the puzzle, we need to rule out the option that the fragments in (2) are well-formed because they underlyingly contain material that is not isomorphic to the antecedent clause. Ellipsis sites need not always be syntactically isomorphic to their antecedent, they may for example correspond to a copula clause containing a cleft structure (van Craenenbroeck 2010, Barros 2012). Our puzzle, however, cannot be explained with reference to a nonisomorphic ellipsis site of this type. To start, paraphrasing the ellipsis site with a pseudocleft does not eliminate the problem of contradictoriness:

(8) A: What are you devouring?

B: \# What I am devouring is a pizza, but I am not devouring it.

The only theoretical possibility would therefore be to analyze the remnant as the pivot of a simple it-cleft, with no relative clause following it, cf. (9). ${ }^{\text {ii }}$

(9) A: What are you devouring?

B: A pizza <it is>.

However, this possibility can be eliminated as well, on the basis of the testimony of languages with overt case marking, like Hungarian or Russian. In these languages pivots of clefts can only be nominative. The remnant in a Pom Pom answer, however, is always marked for the case of its correlate (the wh-phrase) 
and in cases where the correlate is accusative, the fragment cannot show up in the nominative (cf. 10B, B'). In addition to this, Hungarian (just as Russian) has the property that $i t$-clefts are not fully acceptable answers to wh-questions (thus the ?* mark in B"), making it very unlikely that the source of the fragment is an it-cleft to begin with.

$\begin{array}{lll}\text { (10) A: } & \text { Mit faltál } & \text { Hungarian } \\ & \text { what.ACC devour.PST.2SG up } & \\ & \text { What have you devoured?' } & \\ \text { B: } & \text { Egy pizzát. De nem felfaltam, } & \text { hanem } \\ & \text { a pizza.ACC but not up.devour. PST.1SG but } \\ & \text { szépen megettem! } & \\ & \text { nicely PRF.eat.PST.1SG } \\ \text { 'A pizza. But I haven't devoured it, I have eaten it nicely!' } & \\ \text { B': \# } & \text { Egy pizza. } \\ \text { a pizza.NOM } & \\ \text { B": ? } & \text { Egy pizza } \\ \text { a polt az. } & \\ \text { 'It was a pizza.' } & \end{array}$

That the remnant necessarily bears the case (accusative) assigned by a transitive verb is most readily accounted for by assuming that there is silent structure in the ellipsis site with a transitive lexical verb in it, as is done in structural accounts to ellipsis. ${ }^{\text {iii }}$ Non-structural approaches (also called direct interpretation approaches), not assuming syntactic structure and lexical material in the ellipsis site (cf. Stainton 1995, Culicover and Jackendoff 2005, Sag and Nykiel 2011, Ginzburg 2012), need a kind of case-identity constraint to apply to the remnant and its correlate to derive case matching. As I consider structural accounts more parsimonious in this respect, the rest of the paper aims to develop a structural approach to Pom Pom fragments, in search of the lexical elements contained in the silent structure.

\section{Possible solutions}

This section presents a solution in two steps: first proposing an account that is based on accommodation of the lexical content of the ellipsis site, which turns out to be untenable in structural accounts due to violations of syntactic and lexical identity. In light of this I will opt for a solution in terms of mixed quotation in the ellipsis site.

\subsection{Accommodation of lexical content}

This solution is specifically designed for the most natural dialogues with manner verbs (cf. 2), and proposes that Pom Pom answers respond to an accommodated (in the sense of modified, repaired) antecedent, following observations that elided material can be reduced compared to their antecedent (first and foremost Thoms 2013, but see also Johnson 2012, Rooryck \& Schoorlemmer 2014, Den Dikken 2016 among others). Thoms (2013) shows that elliptical material can ignore adjunct material in the antecedent, such as the manner adverb in (11a) or the expressive adjective in (11b) (the latter from Potts et al 2009): 
(11) a. Britain would blindly follow America into Afghanistan, without questioning why <Britain would follow American into Afghanistan>.

b. A: I saw your damn dog in the park.

B: No, you didn't $<$ see my dog in the park $>$ - you couldn't have. The poor thing passed away last week.

In these examples the italicized adjuncts are missing from the ellipsis site, due to a pragmatically induced accommodation step, which is limited by the requirement that the altered antecedent be logically entailed by the original one (see Thoms 2013 for details).

Following the spirit of Thoms' analysis, we can design an account in which the manner component of a verb is ignored by the ellipsis in Pom Pom answers by assuming that these answers do not answer to the explicit question being asked, but to an implicit Question Under Discussion (QUD, see Reich 2007 and Weir 2014 for the QUD-anaphoricity of fragments). This QUD is reduced compared to the original question in that it contains a less specific verb that must be entailed by the original verb. For the example of (2a), the QUD is not Where are you running to? but rather Where are you going to?, which contains the modified ("weakened") predicate as compared to the original one. The manner component is ignored because providing the answer to the weaker question, the addressee still satisfies the communicational goal of the questioner, which is to find out about the value of the $w h$-variable in the question.

To formalize this intuition, I borrow the notion at-issue and non-at-issue content from the literature (see for example Simons et al 2010, Tonhauser 2012, AnderBois 2011, AnderBois et al 2013). At-issue content is content with which the speaker contributes directly to the common ground and expects his communication partner to respond to, via answering a question or acknowledging the content of an assertion. Non-at-issue content on the other hand finds its way into the common ground indirectly, not expecting a response.

The proposal for the Pom Pom dialogues in (2) can thus be that the hearer of the question dissociates the two kinds of content in the original question: the atissue content that corresponds to the weakened verb (entailed by the original predicate) and the non-at-issue manner ingredient that corresponds to an implicature, as shown in (12) for (2c).

$$
\begin{array}{ll}
\text { at-issue: } & \lambda x . \exists \text { e. EAT }(e) \wedge \operatorname{AGENT}(e, \text { you }) \wedge \operatorname{THEME~}(e, x) \\
\text { non-at-issue: } & \text { manner-of-devouring }(e)
\end{array}
$$

The at-issue content is the QUD and gets answered by the fragment. The non-atissue content on the other hand is not part of the QUD, and this is what the correction after the fragment responds to.

$$
\begin{array}{ll}
\text { fragment: } & (\text { a pizza) } \lambda x . \exists \text { e. EAT }(\mathrm{e}) \wedge \operatorname{AGENT}(\mathrm{e}, I) \wedge \text { THEME }(\mathrm{e}, \mathrm{x}) \\
\text { correction: } & \neg \text { manner-of-devouring }(\mathrm{e})
\end{array}
$$

Crucially, the splitting of the two types of content is only permitted if the non-at-issue content gets responded to in the utterance: without a correction, the fragment cannot be interpreted as a weaker proposition than the antecedent. In other words, accommodation must be signaled via linguistic means (Fox 2000). 
The linguistic items doing the signaling must minimally contain the negated verb and preferably a contrastive particle like but.

(14) Q: What are you devouring?

A: A pizza. \#(But) I am not devouring it.

In sum, the gist of this first account is that the original verb's denotation, specifically the extra meaning component in devour as compared to eat for example, is part of the non-at-issue content and ellipsis can ignore this content. The latter statement is not new: Potts et al (2009) has stated that non-at-issue content represented in the form of expressives can be ignored by ellipsis identity (cf. 11b). Pom Pom dialogues make it seem that non-at-issue content can also be ignored by ellipsis if that content is not tied to an expressive.

\subsection{Problems of this account for structural approaches}

While the proposal in 4.1. links the facts to other types of accommodation observed in ellipsis, it runs into non-evident problems when it comes to the representation of the ellipsis site. Assuming that there is structure in the ellipsis site, and that structure is projected from lexical elements, the proposal boils down to using novel lexical material (e.g. eat instead of devour) in the syntactic representation of the ellipsis site. This brings many problems with it, as we demonstrate in this section: in some cases, the required verbs do not exist as independent lexical items, and when they do, they might have a distinct argument structure from their antecedent, or distinct selectional/case properties. Last, all examples (sometimes multiply) violate the lexico-syntactic identity condition on ellipsis called no new words.

To start the discussion with the latter problem, the no new words condition is a condition on ellipsis identity banning novel lexical material from the ellipsis site, originally stated in Chung (2006, ex. 29) as (15).

(15) Every lexical item in the numeration of the sluice that ends up (only) in the elided IP must be identical to an item in the numeration of the antecedent $\mathrm{CP}$.

Chung proposed (15) as a constraint ruling out sluicing with an elided novel preposition or a noun (cf. *They are jealous, but it is unclear who <they are jealous of>, *She read, but we are not sure by which author <she read something>), stating that the condition might apply to ellipsis in general. In some works (cf. Merchant 2013a,b), this condition indeed figures as a general identity condition on ellipsis, and is used to explain ungrammaticality of voice mismatches and argument structure mismatches inside ellipsis sites. ${ }^{\text {iv }}$

How severe the violation of the no new word condition is in the case of Pom Pom answers, depends on the example. For (2a) and (2b) we can supply go instead of run and eat instead of devour, introducing only one new lexical item. In the case of (2c), however, the "weakened" verb - most likely talk or speak - differ in selectional properties from the original shout as they do not take a DP argument, but a PP argument in English.

(16) A: Who are you shouting at?

B: My sister $<\mathrm{I}$ am talking/speaking to $>$, but I am not shouting. 
This violates the no new word condition twice: as both talk/speak and to are novel lexical items. This problem is aggravated in Hungarian, where supplying speak instead of shout would entail distinct cases on the internal argument: üvölt 'shout' assigns sublative, but beszél 'speak' assigns allative. Case connectivity, however, requires the fragment to be in the original case, sublative, ruling out the speak-type verb beszél (with allative) in the ellipsis site:
A: Kire üvöltöttél?
who.SUBL shout.PST.2SG
'Who were you shouting at?'
B: A húgom- $\left\{\mathrm{ra} / *_{-h o z}\right\}$ De nem üvöltöttem!
the sister.POSS.1SG-SUBL/ALL but not shout.PST.1SG
'My sister. But I was not shouting!'

Hungarian in fact possesses no lexical verb with the right semantics and the right case-assigning properties to fill the elliptical gap.

Extending the account to verbs without a manner ingredient (cf. 4), is problematic for various reasons. First, it is not immediately clear how to define the non-at-issue content in these cases, as these verbs are not specifying a particular manner (but rather a result or a psychological state, etc instead). Second, finding an appropriate replacement can be difficult. While hate can be replaced by dislike in (4c), the other two examples are problematic. In (4a), the at-issue content can possibly be defined by weakening sleep to lie, on the (questionable) assumption that sleep is a positional verb and entails lie:

$$
\begin{array}{ll}
\text { original question: } & \lambda x \cdot \exists e . \underline{\operatorname{SLEEP}}(\mathrm{e}) \wedge \operatorname{AGENT}(\mathrm{e}, \mathrm{x}) \\
\text { at-issue }(\mathrm{QUD}): & \lambda x \cdot \exists \mathrm{e} . \underline{\operatorname{LIE}(e)} \wedge \operatorname{AGENT}(\mathrm{e}, \mathrm{x})
\end{array}
$$

Another option is to weaken it to the contentless copula be (A: Who is sleeping there? B: Frank <is there>, but he is not sleeping, he is dead.), but this would involve manipulating the original verb's argument structure, not allowed in elliptical constructions elsewhere (Johnson 2001 among others), as be, unlike sleep, is an unaccusative verb.

In (4b), we face another problem. Extracting the result ingredient from open leaves behind a highly bleeched verb, some kind of activity verb with a theme, like transitive affect, in the at-issue content:

(19) original question: $\lambda x . \exists e . ~ O P E N(e) \wedge \operatorname{AGENT}(e$, you $) \wedge \operatorname{THEME}(e, x)$ at-issue (QUD): $\quad \lambda x . \exists e . \underline{\text { AFFECT }}(e) \wedge \operatorname{AGENT}(e, y o u) \wedge \operatorname{THEME}(e, x)$

The problem with affect, however, is that it belongs to the technical/scientific register, it is not used in this meaning in colloquial English. It is unlikely that we can find the right lexical verb for this case, similarly to the problem we have seen in (17).

It must therefore be concluded that the solution in terms of the accommodation of the verb's lexical content cannot be on the right track when approaching the data in structural approaches. Accommodation of the QUD brings with it several problems: difficulties with finding appropriate replacement, argument structure mismatches and selectional/case mismatches 
between antecedent and ellipsis site (unattested in elliptical constructions elsewhere) and violation of the no new word condition. Note that the accommodation account would be a viable solution in non-structural approaches to fragments, where the interpretation of the fragment is the result of composing it with the semantics of the accommodated QUD. Since these accounts do not assume the existence of any lexical verb in the ellipsis site, they do not face the above listed problems.

\subsection{Ellipsis with mixed quotation}

It turns out that a perfectly viable account can also be designed within structural approaches to ellipsis if we allow the ellipsis site to contain the corrected material in its metalinguistic meaning. ${ }^{\mathrm{v}}$ In other words, the corrected element appears in the ellipsis site with metalinguistic reference, quoted from the speaker of the antecedent question. The other elements in the clause are used in their ordinary (non-metalinguistic) sense. The result is that the elliptical clause contains mixed quotation (so-called by Davidson 1979, who defines it as a mix of direct and indirect discourse syntactically). Indicating quotation by quotation marks, we have the following underlying representations:

(20) A: What are you devouring?

B: $\quad$ A pizza $<\mathrm{I}$ am "devouring" $>$, but I am not devouring it.

A welcome result of this analysis is that now the ellipsis site is syntactically completely identical to that of the antecedent question, as mixed quotation always fully shares the syntax with the quoted constituent, concerning syntactic category, argument structure and case assigning properties of the quoted verb as well. ${ }^{\mathrm{vi}}$

When it comes to the semantic representation, the ellipsis site differs from the antecedent in that the semantic contribution of the quoted verb is not the verb's original denotation, but rather, using the free relative paraphrase offered in Maier (2014), whatever the questioner referred to with the verb in the antecedent. This has the effect that the speaker uttering the answer is not committed to the questioner's assertion, i.e. he does not endorse the questioner's characterization of the event when it comes to the verb's lexical content.

Applying Maier's (2014) presupposition-based analysis of mixed quotation to the data (but see Potts 2007 for a different solution), we can say that the use of "devour" in the ellipsis site triggers the presupposition that the interlocutor used the quoted item to refer to a two-place relation $\mathrm{R}$, while the assertion in the question, which Maier (2014) treats as the at-issue content, only contains reference to the relation $R$.

$$
\begin{array}{ll}
\text { at-issue: } & \text { What are you R-ing? } \\
\text { presupposition: } & \text { the interlocutor used the word devour to express R }
\end{array}
$$

This formulation is advantageous, as it captures even the most extreme cases of Pom Pom dialogues, where the meaning of the original verb needs to be "stripped down" to express only some basic relation between the arguments of the verb (see the treatment of $4 \mathrm{a}$ and $4 \mathrm{~b}$ in 18 and 19 above).

The mixed quotation account in fact goes one step further and predicts that the antecedent verb need not even have any evident meaning. Since the semantic 
interpretation of a quote is not computed in terms of the constituent expression, but rather the phonological interpretation thereof, uninterpretable or non-existent expressions can be quoted as well. This is also the case in Pom Pom dialogues. Imagine that A sees B eating something with audible enjoyment and makes up the verb shmoltz on the spot to describe the event, as in (22A). B can answer this question without having ever heard this verb before, to refer to whatever the questioner intended with it. Crucially, B must be able to figure out from the context that $\mathrm{A}$ is referring to his eating something when asking the question.

(22) A: What are you shmoltzing?

B: A pizza. But what do you mean by "shmoltzing"?

at-issue: What are you R-ing?

presupposition: the interlocutor used the word shmoltz to express $\mathrm{R}$

The quotation account thus also neatly explains why contextual clues are so very relevant for the felicity of Pom Pom answers: as the at-issue content only contains reference to a relation, it is the context that allows the hearer of the question to identify what relation the question is about.

Our proposal is tantamount to saying that ellipsis is a strategy that allows the utterer of a fragment not to take responsibility for the choice of words that appear in the ellipsis site. Ellipsis is not the only strategy to achieve this. The addition of an as-parenthetical, as in example (23), can serve the same function in a non-elliptical answer. Note that this example (unlike $3 b$ ) in noncontradictory.

(23) A: What are you devouring?

B: I am — as you put it — devouring a pizza, but I am not devouring it.

A core ingredient of the above account (similar to the accommodation proposal in section 4.1.) is that answerer dissociates two kinds of content in the original question: the at-issue content that asks for the identification of the whvariable and a non-at-issue content, namely the presupposition introducing the quoted string. The at-issue component is answered by the fragment and the presupposition is commented on by the correction. This kind of dissociation seems to be possible under ellipsis, but only if the antecedent verb is not the focus of the utterance, as mentioned in section 2 with reference to example (5). Why focus has this effect is not clear, but it can be noted that disavowing responsibility for particular words is very odd in contrastive focus contexts in general, even in non-elliptical answers, cf. (24), something that supports the proposal (I thank an anonymous reviewer for noting this). ${ }^{\mathrm{vii}}$

A: The kids have eaten lots of things in different ways. What have they DEVOURED?

B: ?\# They have - as you put it - devoured a pizza. But they have not devoured it.

On balance, the above-presented metalinguisitic account for Pom Pom fragments is the most feasible account within a structural framework of ellipsis, because it assumes complete syntactic identity for the ellipsis site, and only makes use of metalinguistic reference (a phenomenon independently needed) in its 
explanation. In this, the proposed structural account is arguably even more parsimonious than a non-structural approach would be to the data, as the latter approach would need two (rather than one) assumptions to account for Pom Pom fragments: a case-identity constraint (to explain facts like 10) and some form of a QUD accommodation process, as described in section 4.1.

\section{Acknowledgements}

I am indebted to Crit Cremers for numerous discussions on Pom Pom dialogues and for his valuable input on all aspects of the proposal. In addition, I thank two anonymous reviewers, the squib editors of Linguistic Inquiry, as well as Lisa Cheng, Peter Culicover, Marcel den Dikken, Lyn Frazier, James Griffiths, Güliz Güneş, Jason Merchant, Jim McCloskey, Andrés Saab, Wataru Uegaki, Andrew Weir and the audience of Fragments (Saarbrücken, 2016) for discussions, data and comments on previous versions of the material. I am also grateful to Colin Ewen, James Griffiths and Heidi Klockmann for sharing their intuitions about the data and to Charissa Jansen for her generous help with online data collection. All errors are mine. This research is funded by NWO (Netherlands Organisation for Scientific Research).

\section{References}

AnderBois, Scott. 2011. Issues and alternatives. Doctoral dissertation. University of California Santa Cruz, Santa Cruz.

AnderBois, Scott, Adrian Brasoveanu and Robert Henderson. 2013. At-issue proposals and appositive impositions in discourse. Journal of Semantics 13: $1-46$.

Barros, Matthew. 2012. Short sources and pseudosluicing: a non-repair approach to island sensitivity in contrastive TP ellipsis. Proceedings from the Annual Meeting of the Chicago Linguistic Society 48: 61-75.

Barros, Matthew. 2014. Sluicing and identity in ellipsis. Doctoral dissertation, Rutgers University, New Brunswick, NJ.

Barrow, Matthew, and Luis Vicente. 2015. A remnant condition of ellipsis. In Proceedings of the 33rd West Coast Conference on Formal Linguistics, ed. by Kyeong-min Kim, Pocholo Umbal, Trevor Block, Queenie Chan, Tanie Cheng, Kelli Finney, Mara Katz, Sophie Nickel-Thompson and Lisa Shorten, 57-66. Somerville, MA: Cascadilla Proceedings Project.

Chung, Sandra. 2006. Sluicing and the lexicon: The point of no return. In Proceedings of Berkeley Linguistics Society, ed. by Rebecca T. Cover and Yuni Kim, 73-92. Berkeley, CA: Berkeley Linguistics Society.

Craenenbroeck, Jeroen van. 2010. Invisible last resort: A note on clefts as the underlying source for sluicing. Lingua 120:1714-1726.

Culicover, Peter W. and Ray Jackendoff. 2005. Simpler syntax. Oxford: Oxford University Press.

den Dikken, Marcel. 2016. Three challenges for constituent ellipsis and their solutions. Paper presented at International Society for the Linguistics of English 4. Poznan, Poland, 19 September 2016.

Davidson, Donald. 1979. Quotation. Theory and decision 11, 1: 27-40.

Fox, Danny. 2000. Economy and semantic interpretation. Cambridge, MA: MIT Press.

Ginzburg, Jonathan. 2012. The interactive stance. Oxford: Oxford University Press. 
Johnson, Kyle. 2001. What VP-ellipsis can do, and what it can't, but not why. In The handbook of contemporary syntactic theory, ed. by Mark Baltin and Chris Collins, 439-479. Malden, MA and Oxford: Blackwell.

Johnson, Kyle. 2012. Towards a better E-givenness. Four invited lectures, Leiden University.

Kasimir, Elke. 2008. Prosodic correlates of subclausal quotation marks. In ZAS Papers in Linguistics 49, ed. by Zygis, Marzena and Susanne Fuchs, 67-77. Berlin: ZAS.

Klewitz, Gabriele \& Elizabeth Couper-Kuhlen. 1999. Quote-Unquote? The role of prosody in the contextualization of reported speech sequences. Interaction and Linguistic Structure 12: 1-34.

Maier, Emar. 2014. Mixed quotation: the grammar of apparently transparent opacity. Semantics and Pragmatics 7, 7: 1-67.

Merchant, Jason. 2004. Fragments and ellipsis. Linguistics and Philosophy 27: 661-738.

Merchant, Jason. 2010. Three kinds of ellipsis. In Context-Dependence, Perspective, and Relativity, ed. by Francois Recanati, Isidora Stojanovic and Neftali Villanueva, 141-192. Berlin: Walter de Gruyter.

Merchant, Jason. 2013a. Polarity items under ellipsis. In Diagnosing syntax, ed. by Lisa Cheng and Norbert Corver, 441-462. Oxford: Oxford University Press.

Merchant, Jason. 2013b. Voice and ellipsis. Linguistic Inquiry 44: 77-108.

Potts, Chris. 2007. The dimension of quotation. In Direct compositionality, ed. by Chris Barker and Pauline Jacobson, 405-431. New York, NY: Holt, Rinehart \& Winston.

Potts, Chris et al. 2009. Expressives and identity conditions. Linguistic Inquiry. 40, 2: 356-366.

Reich, Ingo. 2007. Toward a uniform analysis of short answers and gapping. In On Information Structure, Meaning and Form, ed. by Kerstin Schwabe and Suzanne Winkler, 467-484. Amsterdam: John Benjamins.

Rooryck, Johan \& Erik Schoorlemmer. 2014. Mistaken identity: ellipsis, mismatches and accommodation. Talk given at the annual meeting of the Linguistic Society of America, Minneapolis, MN.

Saab, Andrés. 2016. On bias vehicle change. Syntactic identity and semantic blocking in ellipsis. Ms., Conicet, Buenos Aires. Available at: http://ling.auf.net/lingbuzz/002764 (accessed on 17 July 2018).

Sag, Ivan and Joanna Nykiel. 2011. Remarks on sluicing. In Proceedings of the HPSG11 Conference Department of Linguistics ed. by Stefan Müller, 188208. Washington: CSLI Publications.

Simons, Mandy, Judith Tonhauser, David Beaver \& Craige Roberts. 2010. What Projects and Why. In Proceedings of Semantics and Linguistic Theory 20, ed. by Nan Li and David Lutz, 309-327. Ithaca, NY: CLC Publications.

Stainton, Robert. 1995. Non-sentential Assertions and Semantic Ellipsis. Linguistics and Philosophy 18: 281-296.

Thoms, Gary. 2013. Lexical mismatches in ellipsis and the identity condition. In Proceedings of the North East Linguistics Society 42, ed. by S. Keine \& S. Slogett, 559-572. Amherst, MA: GSLA Publications.

Tonhauser, Judith 2012. Diagnosing (not-)at-issue content. Semantics of UnderRepresented Languages of the Americas 6: 239-254.

Weir, Andrew. 2014. Fragments and clausal ellipsis. Doctoral Dissertation, University of Massachusetts, Amherst, MA. 
${ }^{\mathrm{i}}$ In an on-line judgement task about the dialogues in (2) with British English $(\mathrm{N}=25)$ and Dutch $(\mathrm{N}=36)$ native speakers (none of them linguists), we found that on average $70 \%$ of our informants considered the dialogues to be perfectly natural or only slightly unnatural. Informants had to evaluate the naturalness of the conversations on a scale of 1 to $5.72 \%$ of the English informants and $68 \%$ of the Dutch informants rated the conversations with 4 or 5 .

Speakers who do not readily rate these dialogues as natural come in two types: a small subset finds the answers strictly speaking contradictory. Another subset finds fragments like (2) odd, but accepts them if something mitigating is added to the correction, or if the original question contains more material, like secondary predicates, as in (i) (I thank an anonymous reviewer for making me aware of these nuances):

(i) A: Who was screaming from the rooftop naked earlier?

B: John, but he wasn't screaming as such.

${ }^{i i}$ Here and below, the non-pronounced elliptical material is indicated with $\langle>$ brackets. The precise position of the remnant being inconsequential, all examples follow displacement accounts in which the remnant moves out of the elided chunk (cf. Merchant 2004) without further arguments.

iii In addition to case matching, other types of connectivity, such as binding and scope connectivity as well as voice connectivity, are also satisfied in Pom Pom dialogues. Similarly, the P-stranding generalization (Merchant 2004) is also observed in the languages we were able to check.

iv It must be noted that the no new words condition is not without exceptions: copulas and pronouns in non-isomorphic cleft clauses violate it, and so do functional elements like infinitival to in examples like Decorating for the holidays is easy if you know how <to decorate> (Merchant 2001). As a result, the condition has been criticized and replaced by other conditions in Barros (2014) and Barros \& Vicente (2015). The reason why we consider violations of the no new words condition in Pom Pom answers as a problem in this paper is because they represent cases in which a distinctly non-functional item (a lexical verb) is an elided new word in the ellipsis site. Such exceptions to the no new word condition are not attested elsewhere.

v I thank Andrés Saab and Lyn Frazier for suggesting this solution to me. See also Saab (2016) for the application of this idea to the example in (11b) and the characterization of the semantic identity relation in terms of it.

${ }^{\mathrm{vi}}$ An anonymous reviewer is concerned about the metalinguistic character of the verb in the ellipsis site in this proposal, noting that quoted material normally receives focusrelated accent and deleting focus is often said to be impossible. I do not agree with this assessment when it comes to its premise. First, quotation is not known to involve lexical focus on the quoted material (in addition, the verb in a Pom Pom answer is not new information focus, either, as it is given). Second, while a quote (as an instance of reported speech) can be realized with pitch accent, such accenting is not necessary. Prosodic studies such as Klewitz and Couper-Kuhlen (1998) and Kasimir (2008) have shown that that prosodic marking of a (mixed) quote need not be done by pitch accenting necessarily. It can be done by a change in either the speech rate or the voice quality or by means of a leading/trailing pause (in addition to having no marking at all). Whether these aspects of prosodic marking are compatible with deletion has not been investigated to my knowledge.

${ }^{\text {vii }}$ Further support for the metalinguistic account comes from the observation that other parts of speech, such as nouns, adjectives, adverbs and phrases formed by them can also be corrected in Pom Pom answers, since mixed quotations exist with such entities. This prediction is correct, as illustrated for a corrected noun phrase in (i):

(i) context: Speaker A missed a meeting and wrongly assumes it was held by the director

A: What did the director announce yesterday in the meeting?

B: The new retirement plan. But it was the vice director.

I leave the investigation of these cases for future work. 